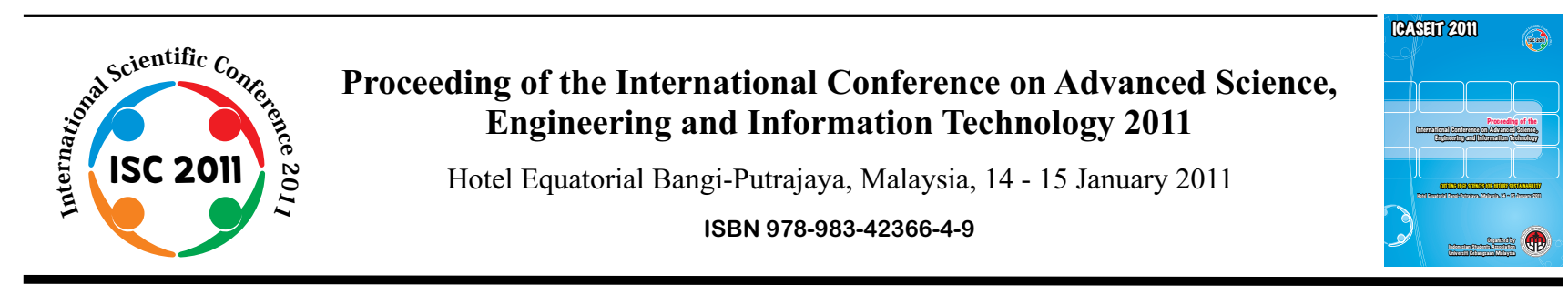

\title{
Investigation into Piston-Slap Force under Friction and Connecting Rod Effects of Diesel Engine
}

\author{
Fuadi Noor Balia ${ }^{\#, *}$, Muhammad Ridha ${ }^{*}$, Shahruddin Mahzan ${ }^{\#}$, Abas AB Wahab \\ " Faculty of Mechanical and Manufacturing Engineering, Universiti Tun Hussein Onn Malaysia \\ Parit Raja, Batu Pahat, 86400, Malaysia \\ Tel.:+6074537903,E-mail:fnbalia@yahoo.co.id,sharudin@uthm.edu.my,abas@uthm.edu.my \\ * Mechanical Engineering Department, Engineering Faculty, Syiah Kuala University \\ Darussalam, Banda Aceh, 23111, Indonesia \\ Tel.:+626517428420,E-mail: ridha.mh@gmail.com
}

\begin{abstract}
In this paper, a dynamics analysis of diesel engine through investigation of the piston-slap force by considering the friction and connecting rod effects is presented. A single-cylinder of $500 \mathrm{cc}$ Diesel Engine's mechanism was examined. The position, velocity and acceleration of the pins and the center of mass for each linkage were calculated by using vector analysis principles. The governing equations of the forces and moments were derived based on the Cartesian coordinate principles, and solved by using Gauss elimination method. Hence, the piston-slap force onto the cylinder wall under friction and connecting rod effects were determined. Favourable comparison with previously published work was performed and excellent agreement between the results was obtained. The result shows that the friction and connecting rod effects significantly influence to the piston-slap force.
\end{abstract}

Keywords - Diesel engine, kinematics and dynamics, vector analysis, friction effect, piston-slap force.

\section{INTRODUCTION}

The use of diesel engines with the environment-friendly fuel resources, such as bio-diesel, becomes popular in many countries [1]-[3]. Therefore, this engine is attractive to be studied.

Vibration analysis is one of the important issues on the diesel engines. One of the sources of vibration on the body structure is generated by piston-slap force. In analyzing the piston-slap force, parameters such as mass of the piston, effects of connecting rod, effects of flywheel and in-cylinder combustion pressure are significantly influential factors [4].

Recently, researches on this area has been being carried out by some researchers [5]-[9]. An in depth investigation from theoretical modeling to experimental verification to correlate the piston-slap impact with the slap induced vibration was carried out by Geng and Chen [5]. The simulation was conducted by considering the mass of piston and angular velocity of diesel engine's crankshaft. However, the friction and the connecting rod effects were not taking into account.
The purpose of this paper is to present the development of a dynamics analysis of diesel engine through investigation of the piston-slap force by considering the friction and connecting rod effects.

Analytical calculations for kinematics that is based on the vector analysis and for dynamics analysis that is based on the Cartesian coordinate principles were applied. Coefficient of friction was taken from the work of Truhan et al. [10]. A single-cylinder of $500 \mathrm{cc}$ (dia. $82 \mathrm{~mm}$ ) diesel engine was taken to be examined. The work of Geng and Chen was used to validate the proposed work.

\section{Problem Formulation}

Analysing the piston-slap force onto the cylinder wall of the engine due to the in-cylinder pressure of combustion process is conducted by two steps, i.e. kinematics and dynamics formulation. Each of the steps can be described as follows: 


\section{A. Kinematic Formulation}

Calculating the position, velocity, and acceleration of pins and center of mass, were developed based on a freely body tilt angle perspective. Vector analysis principles was used to calculate those parameters.

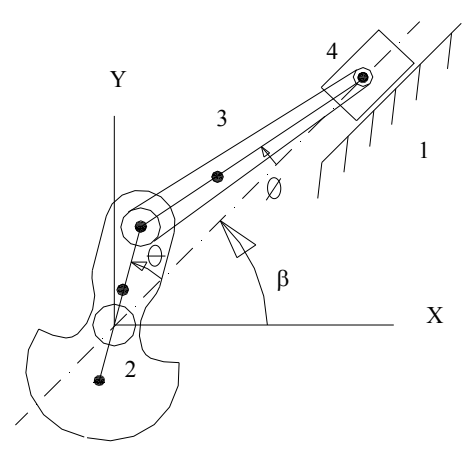

Fig. 1 Mechanism of the Engine

Fig. 1 shows a system of the engine mechanism, in which the body tilt angle was included as a parameter that has the effect to minimize the shaking forces on the engine's crankshaft. Link 1 is cylinder block and journal bearing (fixed), link 2 is the crankshaft (rotation), link 3 is the connecting rod (rotation and translation), and link 4 is the piston (translation) on the cylinder axis.

Fig. 2 shows the vector for kinematic modeling of the engine mechanism that was applied for calculating the position, velocity, and acceleration of pins and mass center of the linkages. In this modeling, $\vec{r}_{2}$ represents the crankshaft, $\vec{r}_{3}$ represents the connecting rod, and $\vec{r}_{4}$ represents the motion line of piston. $\theta_{2}$ is an angle between axis- $\mathrm{x}$ and $\vec{r}_{2}$, $\Delta \theta_{2}$ is an angle between $\vec{r}_{4}$ and $\vec{r}_{2}, \theta_{3}$ is an angle between axis-x and $\vec{r}_{3}, \varnothing$ is an angle between $\vec{r}_{4}$ and $\vec{r}_{3}$, and $\beta$ is an angle between $\mathrm{x}$ axis and $\vec{r}_{2}$.

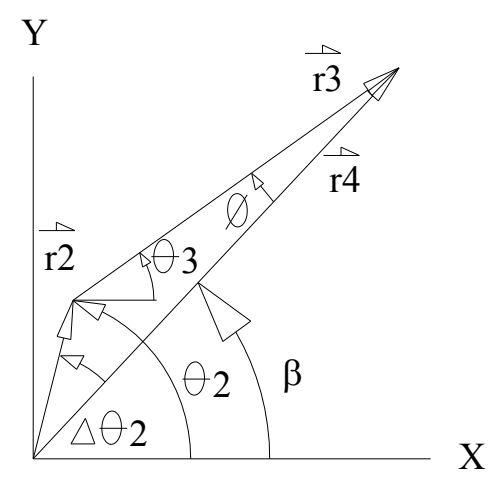

Fig. 2 Kinematic Modeling of Engine Mechanism

From Fig. 2, the mathematical model was governed as a vector equation stated below [4],[11].

$$
\vec{r}_{4}=\vec{r}_{2}+\vec{r}_{3}
$$

This equation (1) was derived to obtain the velocity of points along the line vector, such as stated below,

$$
\dot{\vec{r}}_{4}=\dot{\vec{\theta}}_{2} x \vec{r}_{2}+\dot{\vec{\theta}}_{3} x \vec{r}_{3}
$$

From the equation (2), the angular velocity of the connecting rod was calculated and the result stated as below,

$$
\dot{\theta}_{3}=-\left(\frac{r_{2 x} \cos \beta+r_{2 y} \sin \beta}{r_{3 y} \sin \beta+r_{3 x} \cos \beta}\right) \dot{\theta}_{2}
$$

Equation (2) was derived to give the equation of acceleration of points motion along the cylinder axis, and was written as below,

$$
\ddot{\vec{r}}_{4}=\frac{-r_{2 y} \ddot{\theta}_{2}-r_{2 x} \dot{\theta}_{2}^{2}-r_{3 y} \ddot{\theta}_{3}-r_{3 x} \dot{\theta}_{3}^{2}}{\cos \beta}
$$

Calculation of angular acceleration of linkage 3 , the equation (3) was derived and the result as below,

$$
\ddot{\theta}_{3}=-\frac{A+B+C}{D}
$$

where:

$$
\begin{aligned}
& A=\left(r_{2 x} \cos \beta+r_{2 y} \sin \beta\right) \ddot{\theta}_{2} \\
& B=\left(r_{2 x} \sin \beta-r_{2 y} \cos \beta\right) \dot{\theta}_{2}^{2} \\
& C=\left(r_{3 x} \sin \beta-r_{3 y} \cos \beta\right) \dot{\theta}_{3}^{2} \\
& D=\left(r_{3 y} \sin \beta+r_{3 x} \cos \beta\right)
\end{aligned}
$$

Through equation (1) to equation (5), the position. velocity (linear and angular) and acceleration (linear and angular) of pins and center of mass is obtained.

\section{B. Dynamic Formulation}

Calculation of shaking forces on the pins due to the existing forces at the center of mass of linkage and incylinder pressure, was modeled as Fig. 3 below [4],[11].

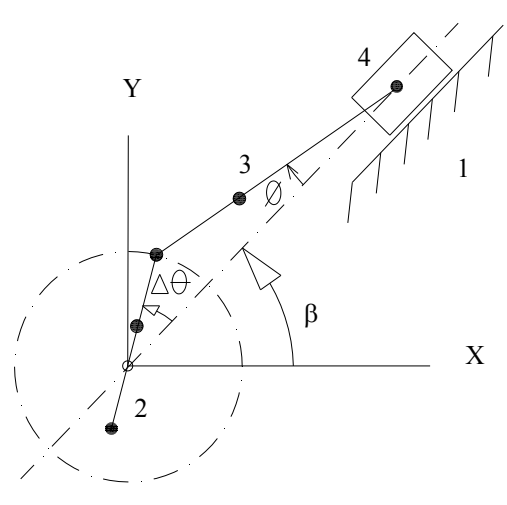

Fig. 3 Dynamic Modeling of Engine Mechanism

This model was solved by using Cartesian coordinate method (vector analysis for dynamic systems) and modeled separately as follows. 


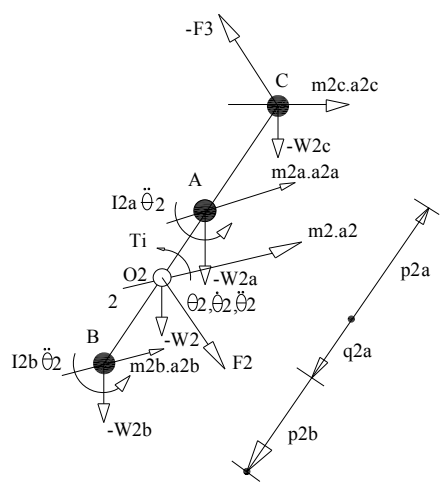

Fig. 4 Modeling of Crankshaft

Fig. 4 shows a physical model of Crankshaft that consists of two parts, crank and balancer. Center of rotation was assumed located at point $\mathrm{A}$, therefore all of the moments in this linkage are referred to this point.

$I_{2 a} \ddot{\vec{\theta}}_{2}$ is generated by rotation of the crank and located at point A. $I_{2 b} \ddot{\vec{\theta}}_{2}$ is generated by rotation of balancer and located at point B. $\vec{T}_{i}$ is the input moment to the shaft due to the reaction of combustion and inertia loads.

$\vec{F}_{2}$ is the reaction of the crankshaft to the crank, while $\vec{F}_{3}$ is the reaction force of crankpin to the crank. $m_{2 a}$ represents the mass of crank and generate the inertia force $m_{2 a} \vec{a}_{2 a}$ and centered at point A. $m_{2 b}$ represents the mass of balancer and generate the inertia force $m_{2 b} \vec{a}_{2 b}$ and centered at point B. $m_{2 c}$ is a half mass of crankpin to the crank, this mass generate a half of inertia force $m_{2 c} \vec{a}_{2 c}$ and centered at point $\mathrm{C}$. In this modeling, the distributed weight of linkage parts are included. $\vec{W}_{2}$ contributes a half of weight of crankshaft, $\vec{W}_{2 a}$ contributes the weight of crank, $\vec{W}_{2 b}$ contributes the weight balancer, and $\vec{W}_{2 c}$ contributes a half of the weight of crankpin.

\section{2) Connecting rod Modeling}

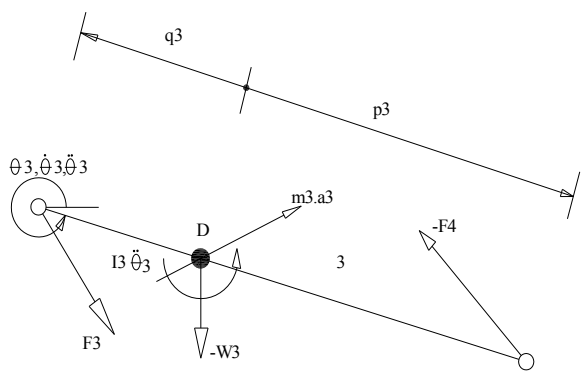

Fig. 5 Modeling of Connecting rod

Fig. 5 shows a physical model of Connecting rod, in which the center of rotation was assumed located at point D.
$I_{3} \ddot{\vec{\theta}}_{3}$ is generated due to the rotation of connecting rod, while $m_{3}$ generate the inertia force $m_{3} \vec{a}_{3}$ and centered at point D. $\vec{F}_{3}$ is the reaction force of crankpin to the connecting rod, while $\vec{F}_{4}$ is the reaction of piston pin to the connecting rod. $\vec{W}_{3}$ represents the connecting rod weight and centered at point $\mathrm{D}$.

\section{3) Piston Modeling}

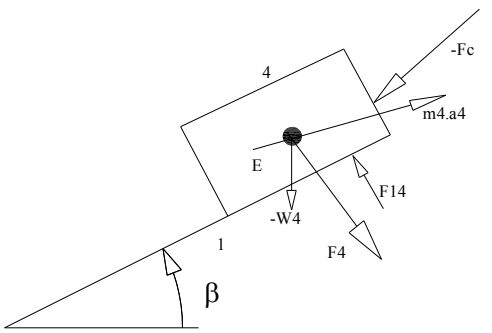

Fig. 6 Modeling of Piston

$\vec{F}_{4}$ represents the reaction force of connecting rod to the pin of piston. The mass $m_{4}$ represents the sum of piston's pin and piston mass itself and generate the inertia force $m_{4} \vec{a}_{4}$ and located at point E. $\vec{W}_{4}$ represents the sum of pin and piston weight. $\vec{F}_{14}$ represents the reaction force of cylinder to the piston and assumed to be located coincident at the center of piston mass, and $\vec{F}_{c}$ represents the incylinder force as a result of the combustion pressure on the frontal area of piston.

\section{Mathematical Equations}

Mathematical equations for dynamics modeling of the mechanism was developed by using Cartesian coordinate principles. Each of linkage had been developed the governing equation, i.e. for crankshaft, connecting rod and piston.

\section{1) Equation for Crankshaft}

Crankshaft was modeled that consists of the crank and the balancer that have only rotation movement, the crank was assumed rotated at point $\mathrm{A}$ and the balancer rotated at point B (Fig. 4).

Equilibrium equations of force vector of the crankshaft is expressed as shown below,

$$
\vec{F}_{2}-\vec{F}_{3}=m_{2 a} \vec{a}_{2 a}+m_{2 b} \vec{a}_{2 b}+m_{2 c} \vec{a}_{2 c}
$$

Equilibrium equation of moment (torque) vector for crankshaft is expressed as shown below,

$$
\begin{aligned}
& \vec{q}_{2 a} \times \vec{F}_{2}-\vec{p}_{2 a} \times \vec{F}_{3}+\vec{T}_{i}= \\
& E+F+G+H+I+J
\end{aligned}
$$


where:

$$
\begin{aligned}
& E=\left(\vec{p}_{2 b}+\vec{q}_{2 b}\right) \times m_{2 b} \vec{a}_{2 b} \\
& F=\left(\vec{p}_{2 b}+\vec{q}_{2 a}\right) \times \vec{W}_{2 b} \\
& G=\vec{q}_{2 a} \times \vec{W}_{2} \\
& H=\vec{p}_{2 a} \times \vec{W}_{2 c} \\
& I=\vec{p}_{2 a} \times m_{2 c} \vec{a}_{2 c} \\
& J=\left(I_{2 a}+I_{2 b}\right) \ddot{\vec{\theta}}_{2}
\end{aligned}
$$

\section{2) Equation for Connecting rod}

Connecting rod was assumed to have translation and rotation movement, and rotated at the point $\mathrm{D}$ (Fig. 5).

Equilibrium equation of the force vector of the connecting rod can be expressed as shown below,

$$
\vec{F}_{3}-\vec{F}_{4}=m_{3} \vec{a}_{3}+\vec{W}_{3}
$$

Equilibrium equation of the moment (torque) vector of the connecting rod and expressed as,

$$
\vec{q}_{3} \times \vec{F}_{3}-\vec{p}_{3} \times \vec{F}_{4}=I_{3} \ddot{\vec{\theta}}_{3}
$$

\section{3) Equation for Piston}

Piston is a sliding body that move only translation. In this case, the equilibrium equation for moment was neglected.

Equilibrium equation of forces of piston can be expressed as shown below,

$$
\vec{F}_{4}+\vec{F}_{14}=m_{4} \vec{a}_{4}+\vec{F}_{c}
$$

in which:

$$
\vec{F}_{14}=\vec{F}_{s}+\vec{F}_{14 N}
$$

\section{4) Matrix Formation}

From the equation of crankshaft, connecting rod, and piston, the amount of equations that are expanded, can be explained below.

The crankshaft contributes three rows of equilibrium equation, in which equation (6) is expanded become two rows of force equations in $\mathrm{x}$ and $\mathrm{y}$ direction, while equation (7) be a row of torque equation.

The connecting rod contributes three rows of equilibrium equation, in which equation (8) is expanded become two rows of force equation in $\mathrm{x}$ and $\mathrm{y}$ direction, and equation (9) result a row of torque equation.

The piston contributes two rows of equilibrium equation, in which equation (10) can be expanded to be two rows of the force equation in $\mathrm{x}$ and $\mathrm{y}$ direction. These components have only the force equation. Equation (11) is a part of equation (10) that consist of the friction effect.

From all of the above equations that has expanded, a simultaneously linear equations that consist of eight rows was governed as a matrix form of equation that consist of matrix coefficient $[A]$ ( $8 x 8$ elements matrix), reaction loads $\{X\}(8 \times 1$ elements matrix), and effective loads $\{B\}(8 \times 1$ elements matrix, including moments and forces of inertia).

These eight of linear equations were governed as a matrix formation as shown below,

$$
[A]\{X\}=\{B\}
$$

The reaction loads $\{X\}$ were solved simultaneously in the form of linear equation using Gauss Elimination method [12].

\section{METHOD OF SOLUTION}

The general steps of solution method for the engine mechanism is explained such as Flowchart in Fig. 7.

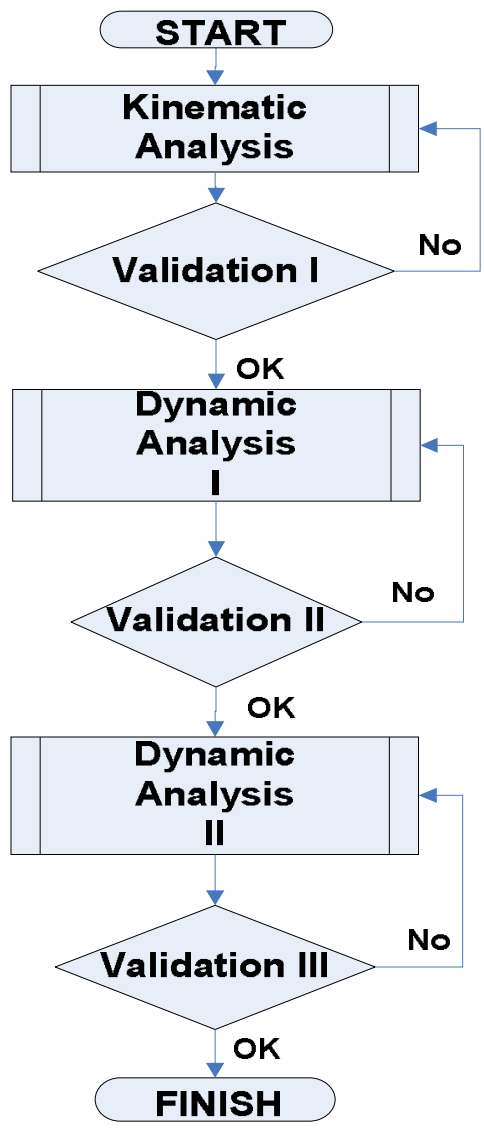

Fig. 7 Flowchart of solution method steps

Visual $\mathrm{C}++6$ compiler was used to calculate the analysis of kinematics and dynamics of the mechanism [13]. The steps of calculation can be explained as follows:

At the step of kinematic analysis, the position, velocity, and acceleration of pins, mass center of each linkage was analysed. Using vector analysis method for free tilt angle, the calculations were performed. Validation I using graphical method was performed.

Dynamic analysis has two steps of calculation, first step without friction and second step with the friction effect on the piston. The analysis can be explained as follows: 
- For the first step, the equilibrium of forces on the piston, only equation (10) be expanded in $\mathrm{x}$ and $\mathrm{y}$ direction. In this step, the in-cylinder pressure and its conversion to the combustion forces data was supplied to the equation (10) according to the crank angle of combustion [14]. The technique of force supply conducted by generating the mathematical equation model for pressure profile [15]. Validation II using static force analysis was performed.

- For the second step, the same procedure is conducted as the first step. For friction effect, the equation (10) is expanded by inserting equation (11) and the forces can be expanded in $\mathrm{x}$ and $\mathrm{y}$ direction. The value of coefficient friction $\mu=0.12$ was taken from the work of Truhan et al. [10]. Special treatment was taken into account in solving friction effect, in which the positive and negative sign of normal force $F_{14 N}$ shown in Fig. 8. Formula for the friction force become $F_{s}=\mu F_{14 N}$. The direction of $F_{s}$ was set in accordance with the crank angle $\theta$ condition, for $0^{\circ} \leq$ $\theta \leq 180^{\circ}$ and $360^{\circ} \leq \theta \leq 540^{\circ}, \quad F_{s}$ is positive, meanwhile for $180^{\circ} \leq \theta \leq 360^{\circ}$ and $540^{\circ} \leq \theta \leq 720^{\circ}$, $F_{s}$ is negative. Validation III was performed by comparing to the work of Geng and Chen [5].

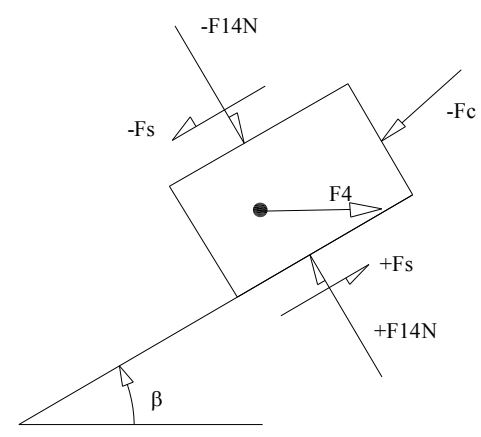

Fig. 8 The sign of normal and friction force on piston modeling

\section{RESULT AND DISCUSSION}

The validation of the proposed work was conducted by adopting the size of engine and was conditioned same as used in the simulation work of Geng and Chen (Fig. 9a). The slightly difference of piston-slap force simulation was caused by the difference of the combustion pressure data profile. In general, however, a good agreement of piston-slap force was achieved between the proposed work and the work of Geng and Chen, as given in Fig. 9b.

The next simulation was carried out by using the proposed size of engine i.e. $500 \mathrm{cc}$ (dia. $82 \mathrm{~mm}$ ), running in $2000 \mathrm{rpm}$ and taking into account the connecting rod effect. Fig. 10a shows the piston-slap force when the friction effect was neglected (the point of TDC at $360^{\circ}$ ) and Fig. 10b shows the piston-slap force by taking into account the friction effect. Anyhow, the connecting rod effect takes place in both of the last figures.

In addition, Table 1 shows the difference of piston-slap forces value when the friction effect was taking into account and neglected, respectively. When it took $\mu=0.12$ the difference of the value took up to 2.4 percents.

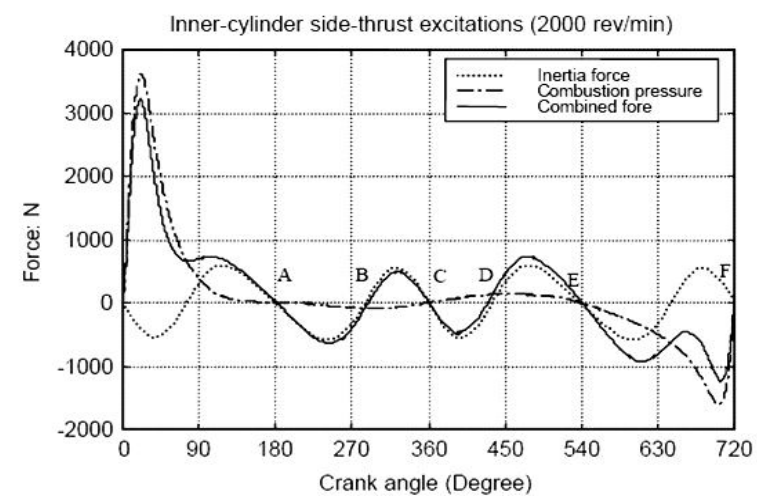

Fig. 9a Piston-slap force as result of Geng's work [5].

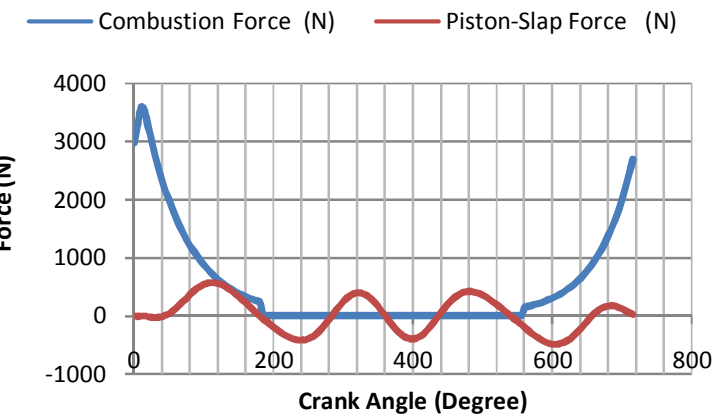

Fig. 9b Piston-slap force as result of proposed work, pressure $=3.5$ bar, without friction and connecting rod effects

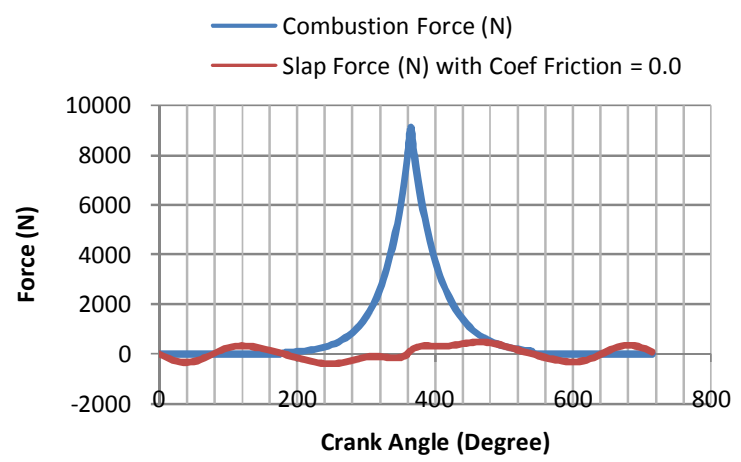

Fig. 10a Piston-slap force for Pressure $=15$ bar, without Friction

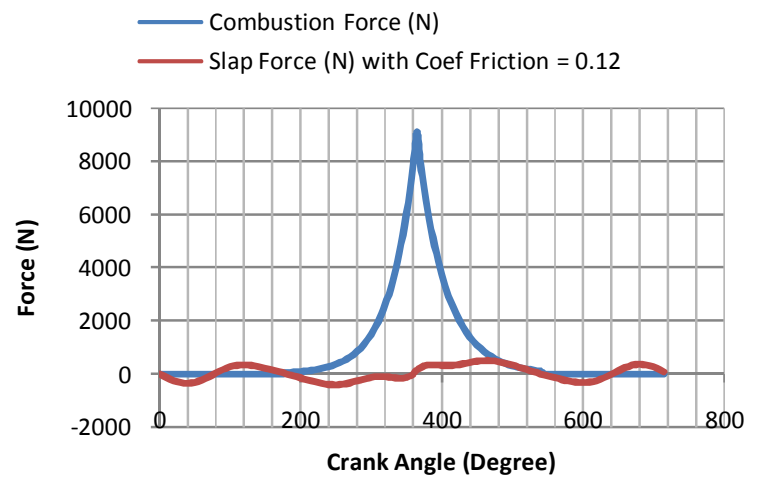

Fig. 10b Piston-slap force for Pressure $=15$ bar, with Friction 
Table 1 Difference of piston-slap force between with and without friction

\begin{tabular}{|c|c|c|c|c|c|}
\hline \multirow{2}{*}{$\begin{array}{c}\theta \\
\text { (deg) }\end{array}$} & \multicolumn{2}{|c|}{$\begin{array}{l}\text { Piston-slap Force } \\
(\mathrm{N})\end{array}$} & \multirow{2}{*}{$\begin{array}{c}\theta \\
\text { (deg) } \\
\end{array}$} & \multicolumn{2}{|c|}{$\begin{array}{l}\text { Piston-slap Force } \\
(\mathrm{N})\end{array}$} \\
\hline & $\mu=0$ & $\mu=0.12$ & & $\mu=0$ & $\mu=0.12$ \\
\hline 0 & 0.00 & 0.00 & 360 & 0.00 & 0.00 \\
\hline 45 & -342.17 & -350.45 & 405 & 312.57 & 320.14 \\
\hline 90 & 153.82 & 159.25 & 450 & 463.02 & 479.36 \\
\hline 135 & 296.64 & 303.82 & 495 & 366.82 & 375.70 \\
\hline 180 & 0.00 & 0.00 & 540 & 0.00 & 0.00 \\
\hline 225 & -333.05 & -341.11 & 585 & -296.64 & -303.82 \\
\hline 270 & -337.61 & -349.53 & 630 & -153.82 & -159.26 \\
\hline 315 & -103.72 & -106.23 & 675 & 342.17 & 350.45 \\
\hline
\end{tabular}

\section{CONCLUSIONS}

The dynamics analysis of diesel engine through investigation of the piston-slap force by considering the friction and connecting rod effects was conducted.

Analytical calculations for kinematics and dynamics analysis were applied. Kinematics analysis was based on the vector analysis and dynamics analysis was based on the Cartesian coordinate principles. The validation of the proposed calculation work was performed by comparing the result with the work of Geng and Chen, in which the friction and connecting rod effects were neglected.

Special treatment was considered in solving friction effect, in which the positive and negative signs of normal force can result the friction force. The direction of friction force was set in accordance with the crank angle condition. The result shows that the friction and connecting rod effects were significantly affected to the piston-slap force.

The proposed work has a good achievement for dynamic analysis of engine use, with the adjustable tilt angle.

Further study is needed to understand the effects of friction and connecting rod to other loads such as output torsion and shaking forces on crankshaft.

\section{NOMENCLATURE}

$\vec{r}_{n} \quad$ position vector for link $\mathrm{n}$

$\mathrm{m}$

$r_{n x} \quad$ length of position vector link $\mathrm{n}$ in $\mathrm{x}$ axis

$\mathrm{m}$

$r_{n y} \quad$ length of position vector link $\mathrm{n}$ in $\mathrm{y}$ axis

$\mathrm{m}$

$\dot{\vec{r}}_{n} \quad$ linear velocity vector of link $\mathrm{n}$

$\ddot{\vec{r}}_{n} \quad$ linear acceleration vector of link $\mathrm{n}$

$m_{n i} \quad$ mass of link $\mathrm{n}$ at center $\mathrm{i}$

$I_{n i} \quad$ mass moment of inertia of link $\mathrm{n}$ at center $\mathrm{i}$

$\vec{T}_{i} \quad$ input torque for balancing

$\vec{a}_{n i} \quad$ linear acceleration of link $\mathrm{n}$ at center $\mathrm{i}$

$\vec{W}_{n i} \quad$ weight of link $\mathrm{n}$ at center $\mathrm{i}$

$\vec{p}_{n i} \quad$ length of position vector of link $\mathrm{n}$ at center $\mathrm{i}$

$\vec{q}_{n i} \quad$ length of position vector of link $\mathrm{n}$ at center $\mathrm{i}$

$\mathrm{m} / \mathrm{sec}$

$\mathrm{m} / \mathrm{sec}^{2}$ $\mathrm{kg}$

$\mathrm{kg}-\mathrm{m}^{2}$

$\mathrm{N}-\mathrm{m}$

$\mathrm{m} / \mathrm{sec}^{2}$

$\mathrm{N}$

$\mathrm{m}$

$\mathrm{m}$

$\vec{F}_{n} \quad$ force vector of link $\mathrm{n}$

$\vec{F}_{c} \quad$ force vector of combustion process

$\vec{F}_{14}$ force vector of cylinder wall to the piston

$F_{14 N}$ normal force of cylinder wall to the piston
$F_{S}$

$\mu$

friction force of cylinder wall to the piston $\mathrm{N}$ coefficient of friction

Greek letter

$\theta_{n} \quad$ angle between $\mathrm{x}$-axis to link $\mathrm{n}$

$\Delta \theta_{n} \quad$ angle between cylinder-axis to link $\mathrm{n}$

$\emptyset \quad$ angle between cylinder-axis to link 3

$\beta \quad$ angle between $\mathrm{x}$-axis to cylinder-axis

$\dot{\theta}_{n} \quad$ angular velocity of link $\mathrm{n}$

$\ddot{\theta}_{n} \quad$ angular acceleration of link $\mathrm{n}$

$m_{n} \vec{a}_{n}$ inertia force vector of link $\mathrm{n}$

$I_{n} \ddot{\vec{\theta}}_{n} \quad$ inertia torque vector of link $\mathrm{n}$

degree

degree

degree

degree

$\mathrm{rad} / \mathrm{sec}$

$\mathrm{rad} / \mathrm{sec}^{2}$

$\mathrm{N}$

$\mathrm{Nm}$

Matrix

$[A] \quad$ coefficient matrix of $8 \times 8$

$\{X\} \quad$ reaction load matrix of $8 \times 1$

$\{B\} \quad$ load matrix of $8 \times 1$

$\mathrm{N}$

$\mathrm{N}$

\section{ACKNOWLEDGMENT}

We would like to thank to our colleague Dr. Muhaimin Ismoen, Applied Mathematician at Center of Science Studies UTHM on his support with fully fresh fruits discussion on the Mathematical Problems.

\section{REFERENCES}

[1] A.K. Agarwal, "Biofuel (alcohols and biodiesel) applications as fuel for internal combustion engines", Progress in Energy and Combustion Science, vol. 33, pp. 233-271, Nov. 2006.

[2] A.S. Ramadhas, S. Jayaraj, and C. Muraleedharan, "Use of vegetable oil as IC engine fuel: A review", Renewable Energy, vol. 29 , pp. 727-742, Sept. 2003.

[3] A. Murugesan, A. Umarani, R. Subramanian, and N Nedunchezian, "Bio-diesel as an alternative fuel foe diesel engines", Renewable and Sustainable Energy Reviews, Oct. 2007.

[4] R.L. Norton, Design of Machinery : Introduction to the Synthesis and Analysis of Mechanisms and Machines, Fourth Edition, McGraw-Hill, 2008.

[5] Z. Geng, and J. Chen, "Investigation into piston-slap-induced vibration for engine condition simulation and monitoring", Sound and Vibration, vol. 282, pp. 735-751, March 2004.

[6] P. Metallidis, S. Natsiavas, "Linear and nonlinear dynamics of reciprocating engines", International Journal of Non-Linear Mechanics vol. 38, pp. 723-738, 2003.

[7] A.P. Garlucci, F.F. Chiara, and D. Laforgia, "Analysis of the relation between injection parameter variation and block vibration of an internal combustion diesel engine", Sound and Vibration, vol 295, pp. 141-164, April 2006.

[8] E. Brusa, C. Delprete, and G. Genta, "Torsional Vibration of Crankshaft: Effects of Non-Constant Moments of Inertia", Sound and Vibration, vol 205, pp. 135-150, Feb. 1997.

[9] A.L. Guzzomi, D. C. Hesterman, and B. J. Stone, "The effect of piston friction on the torsional natural frequency of a reciprocating engine", Mechanical Systems and Signal Processing, pp. 2833-2837, Feb. 2007.

[10] J. J. Truhan, J. Qu, and P. J. Blau, "A rig test to measure friction and wear of heavy duty diesel engine piston rings and cylinder liners using realistic lubricants", Tribology International, vol. 38, pp. 211-218, 2004.

[11] F.P. Beer, and E.R. Johnston. Jr, Vector Mechanics for Engineers, Statics \& Dynamics, Eighth Edition, McGraw-Hill, 1997.

[12] W.H. Press, S.A. Teukolsky, W.T. Vetterling, and B.P. Flannery, Numerical Recipes in $\mathrm{C}++$ : The Art of Scientific Computing, Second Edition, Cambridge University Press, 2002.

[13] I. Horton, Beginning Visual C++ 6, Wrox Press, 1998.

[14] J.B. Heywood, Internal Combustion Engine Fundamentals, McGraw-Hill, 1988.

[15] E. J. Purcell, D. Varberg, Calculus with Analytic Geometry, Fourth Edition,Prentice-HallInc., 1984. 